\title{
Legislação ambiental e degradação ambiental do solo pela atividade petrolífera no Brasil
}

\section{Environmental Legislation and Environmental Degradation of the Soil by Oil Activity in Brazil}

\author{
Carlos José Saldanha MACHADO* \\ Rodrigo Machado VILANI** \\ Marcio Gonçalves FRANCO*** \\ Siomara Dias da Costa LEMOS ${ }^{* * * *}$
}

\begin{abstract}
RESUMO
Os objetivos deste trabalho são: $i$ ) analisar a degradação ambiental resultante da intensa atividade antrópica, particularmente a contaminação do solo, sob a perspectiva do desenvolvimento sustentável e da legislação ambiental brasileira, e ii) contribuir para a superação das lacunas encontradas na regulamentação e nas políticas públicas voltadas para a proteção dos solos no país e para futuras pesquisas empíricas de avaliação dos impactos ambientais, reais e potenciais, causados pelo petróleo e seus derivados ao solo. Após uma análise bibliográfica de textos sobre solo, políticas públicas, desenvolvimento sustentável, direito ambiental e Política Nacional do Meio Ambiente e do arcabouço legal relativo à legislação federal em vigor até março de 2012, sob a perspectiva do desenvolvimento sustentável, são apontados os pontos de aproximação e distanciamento entre as disposições legais e conceituais acerca da sustentabilidade e a realidade das práticas governamentais em relação à manutenção da qualidade do solo no Brasil. Conclui-se afirmando que há uma ausência de regulamentação clara sobre a poluição do solo causada por petróleo e derivados e o seu tratamento é considerado de forma secundária, o que dificulta uma integração entre o desenvolvimento da atividade petrolífera no país e a conservação da qualidade do solo para as presentes e futuras gerações.
\end{abstract}

Palavras-chave: degradação ambiental; solo; petróleo; políticas públicas; desenvolvimento sustentável.

\footnotetext{
* Doutor em Antropologia Social (Université PARIS 5, Sciences Sociales Sorbonne). Pesquisador da Fundação Oswaldo Cruz (Fiocruz) e Professor dos Programas de Pós-Graduação em Biodiversidade e Saúde (PPGBS-IOC) da Fiocruz e em Meio Ambiente (Doutorado) da Universidade do Estado do Rio de Janeiro (PPG-MA/ UERJ).E-mail: saldanha@fiocruz.br

"* Doutor em Meio Ambiente (UERJ). Professor do Mestrado em Planejamento Regional e Gestão de Cidades da Universidade Candido Mendes (UCAM/Campos dos Goytacazes).E-mail: r_vilani@yahoo.com.br

*** Doutor em Meio Ambiente (UERJ). Professor da Fundação Técnico-Educacional Souza Marques (FTESM) e da Universidade do Grande Rio (UNIGRANRIO) E-mail: marciogoncalvesfranco@gmail.com

***** Mestra em Biologia Celular e Molecular (PUC-RS). Doutoranda do Programa de Pós-Graduação Multidisciplinar de Meio Ambiente da Universidade do Estado do Rio de Janeiro (UERJ).E-mail: lemos.sdc@uerj.br
} 


\begin{abstract}
The aims of this study are: i) to analyze the environmental degradation resulting from intense anthropic activity, particularly the soil contamination, from the perspective of sustainable development and Brazilian environmental legislation, and ii) to contribute to overcoming the gaps found in the regulation and public policies aimed at soil protection in the country and to future empirical evaluation of actual and potential environmental impacts caused by oil and its derivatives to soil. A literature review was conducted with bibliography on soil, public policies, sustainable development, environmental law, National Environmental Policy, and legal framework related to federal legislation in force until March 2012. Also, based on the perspective of sustainable development, points of approach and distance between legal and conceptual provisions about sustainability and the governmental practices related to soil quality maintenance in Brazil are highlighted. We conclude stating the lack of clear regulation about soil pollution caused by oil and its derivatives, and the treatment of this pollution being considered secondarily, hindering an integration between the development of oil activity in the country and preservation of soil quality for present and future generations.
\end{abstract}

Keywords: environmental degradation; soil; oil; public policies; sustainable development.

\section{Introdução}

Atividades de mineração, práticas agronômicas, aplicação de efluentes industriais ou lodo para irrigação de plantações são as maiores fontes de contaminação em terras para agricultura (CHANDRA et al., 2009, p. 1.514). A cobertura vegetal danificada em áreas contaminadas por elementos tóxicos amplia a degradação do solo, resultando na erosão hídrica e eólica, assim como na lixiviação dos contaminantes para o lençol freático. Este fenômeno pode ocasionar um grau progressivo de contaminação de outras áreas, sendo próximas ou não (MELO et al., 2009, p. 456).

Devido à grande degradação que os recursos naturais vêm sofrendo nas últimas décadas, constata-se uma preocupação crescente de segmentos expressivos da população com a preservação do ambiente e destes recursos. Tal preocupação objetiva conquistar a manutenção da qualidade de vida e buscar um desenvolvimento sustentável por meio de um equilíbrio entre o ambiente natural, o seu uso econômico e a redução das desigualdades sociais (MACHADO, 2012; OLIVEIRA e SOUTO, 2011, p. 1).

Nesse sentido, desde a década de 1970 uma série de conferências e iniciativas internacionais tem auxiliado a divulgar conceitos importantes que permitam um melhor entendimento do planeta em que vivemos e criar políticas públicas para um desenvolvimento sustentável. Esta inter-relação entre várias áreas do saber e vários atores é importante para realizar o estudo do meio ambiente, visto que este estudo é transdisciplinar (OLIVEIRA e SOUTO, 2011, p. 1).

Segundo Avanzi e colaboradores (2009, p. 116), a preservação dos recursos naturais, principalmente da água e do solo que seriam interdependentes, é necessária para obter-se uma qualidade ambiental adequada. Esta inter-relação permite a vida dos biomas, assim como os habitats das espécies e a variedade das paisagens, florestas e plantações. Segundo os mesmos autores, no Brasil a utilização dos solos caracterizou-se pela atividade agrícola desde a colonização, sempre estimulada pela economia cíclica e migratória (AVANZI et al., 2009).

Mas o surgimento de áreas degradadas no mundo é cada vez mais crescente. No Brasil, esta degradação é basicamente resultado de atividades antrópicas decorrentes do crescimento econômico, tais como construção de estradas, atividades industriais e agrícolas mal planejadas, que têm resultado em $10 \%$ da área do país degradada e em processo de desertificação e arenização. Este processo se intensifica com a combinação do regime climático, dos solos frágeis e do rápido desenvolvimento econômico que ocorre no território nacional e em outros países (OLIVEIRA e SOUTO, 2011, p. 3).

Além de ser uma superfície que recobre o planeta Terra, o solo é a estrutura responsável pelo suporte bá- 
sico à vida no planeta. Tal fato se deve a esta estrutura agir direta ou indiretamente na purificação da água, detoxificando os poluentes ali presentes, restaurando ecossistemas, favorecendo a ciclagem de nutrientes e favorecendo o ciclo da água. O solo também possui organismos, matéria orgânica, sais e minerais que, em equilíbrio, permitem a vida da Terra (DINIZ FILHO et al., 2007, p. 28).

Apesar de sua importância, há uma notável escassez de dados em relação à contaminação dos solos por hidrocarbonetos, compostos considerados persistentes por longo período no ambiente se comparados com aqueles disponíveis para a contaminação de ecossistemas aquáticos (MARANHO et al., 2009, p. 264).

A consolidação de pesquisas para suprir essa lacuna releva-se, por exemplo, da constatação de que:

Os hidrocarbonetos aromáticos policíclicos (HAPs) são compostos mutagênicos e carcinogênicos aos humanos e aos animais, que são introduzidos no ambiente em grandes quantidades devido às atividades relacionadas à extração, ao transporte, ao refino, à transformação e à utilização do petróleo e de seus derivados. Apesar disso, a grande maioria dos microrganismos do solo não possui a capacidade de degradá-los, o que resulta na sua acumulação no ambiente e na consequente contaminação dos ecossistemas (JACQUES et al., 2007. p. 1.192).

Diante deste cenário, o objetivo deste trabalho é analisar a degradação ambiental resultante da intensa atividade antrópica, particularmente a contaminação do solo, sob a perspectiva do desenvolvimento sustentável e da legislação ambiental brasileira. Enquanto conceito estruturante do trabalho, desenvolvimento sustentável será definido a partir do texto constitucional (art. 3, II c/c. art. 170, caput, VI e art. 225, caput.) como aquele que se propõe garantir o desenvolvimento nacional em conformidade com uma ordem econômica socialmente justa e ambiental equilibrada. Dessa forma, procura-se contribuir para a superação das lacunas encontradas na regulamentação e nas políticas públicas voltadas para a proteção dos solos no país e para futuras pesquisas empíricas de avaliação dos impactos ambientais, reais e potenciais, causados por petróleo e seus derivados ao solo. Metodologicamente, optamos pela pesquisa biblio- gráfica (artigos, livros, teses e dissertações) abrangendo os temas centrais do trabalho: solo, políticas públicas, desenvolvimento sustentável, direito ambiental e Política Nacional do Meio Ambiente. Para o aprofundamento dos temas, sob a perspectiva jurídica, foi realizada pesquisa sobre o arcabouço legal relativo à legislação federal em vigor até março de 2012.

Além desta Introdução, o trabalho está organizado em quatro seções. Inicialmente, é apresentado o objeto central do estudo, delimitando os conceitos de solo e qualidade do solo. Em seguida, tratamos sucintamente da industrialização da economia brasileira no século XX, voltando nosso olhar especificamente para a produção de hidrocarbonetos de petróleo e seus impactos sobre o solo. Para se discutir o papel do Estado na gestão e na defesa do uso racional do solo, na terceira seção são analisadas, sob a perspectiva do desenvolvimento sustentável, as políticas públicas nacionais e a legislação ambiental vigente durante o mesmo período. Na última seção, antes de concluir, é feito um breve resumo dos principais eventos mundiais de meio ambiente e seus impactos na mudança ou continuidade do perfil da política nacional de meio ambiente. Do cenário traçado passamos a uma reflexão quanto aos pontos de aproximação e distanciamento entre as disposições legais e conceituais acerca da sustentabilidade e a realidade das práticas governamentais em relação à manutenção da qualidade do solo no Brasil. A título de considerações finais, levantamos as lacunas das políticas ambientais brasileiras para a superação dos desafios relacionados à defesa dos recursos ambientais, em particular, do solo.

\section{Solo e qualidade do solo}

Existem vários conceitos de solo, todos estes ligados a várias áreas do saber no qual este elemento está direto ou indiretamente relacionado. Segundo Diniz Filho e colaboradores $(2007$, p. 28) o solo é definido como:

Conjunto de corpos tridimensionais que ocupa a parte superior da crosta terrestre capaz de servir de suporte para as plantas, apresentando características internas e externas próprias possíveis de descrevê-las e classificá-las. 
Segundo a International Organization for Standardization - ISO - 11074/1, o solo é definido como a camada superficial da crosta terrestre constituída por partículas minerais, matéria orgânica, água, ar e organismos vivos. As interações entre os seus constituintes resultam em suas propriedades químicas, físicas e biológicas, o que permite aos cientistas considerar o solo como um sistema complexo.

Devido a esta complexidade, Rozanski (2004, apud OLIVEIRA e SOUTO, 2011, p. 1) descreve que:

[...] a fauna do solo tem importante papel na sustentabilidade do sistema através de seus efeitos nos processos do solo, e devido a sua grande sensibilidade às interferências no ecossistema, a composição da comunidade pode refletir o padrão de funcionamento do mesmo.

Deve-se destacar que é importante diferenciar o solo superficial e o subsolo. O primeiro caracteriza-se como a região onde ocorre o desenvolvimento vegetal, onde as plantas desenvolvem as suas raízes, em uma região de $30 \mathrm{~cm}$ até $1 \mathrm{~m}$ e $50 \mathrm{~cm}$; já o segundo é a região além da anterior, passando de $1 \mathrm{~m}$ e $50 \mathrm{~cm}$, que fornece o suporte de nutrientes e umidade, sendo também importante em situações de contaminações da água subterrânea (ADAMS et al., 2008, p. 483).

Caracterizado o solo, podemos deduzir que as suas características físicas e químicas podem ser alteradas dependendo da substância química que entra em contato com ele. Segundo Adams e colaboradores (2008, p. 484), se levarmos em consideração a fertilidade para produção de fitomassa e desenvolvimento de uma população vegetal natural, é provável que muitas áreas com hidrocarbonetos de petróleo residuais possam afetar o solo. Sendo assim, segundo estes autores, seria recomendável realizar nestas áreas um diagnóstico sobre as propriedades químico-físicas e um tratamento para recuperar este solo.

Em suas perfeitas condições, o solo funciona dentro dos limites do ecossistema e permite a produtividade biológica. Doran (1997, apud VEZZANI e MIELNICZUK, 2009, p. 744) define qualidade do solo como:

[...] a capacidade de um solo funcionar dentro dos limites de um ecossistema natural e manejado, para sustentar a produtividade de plantas e animais, manter e aumentar a qualidade do ar e da água e promover a saúde das plantas, dos animais e dos homens.

Segundo Vezzani e Mielniczuk (2009, p. 744), o Serviço de Conservação dos Recursos Naturais do Departamento de Agricultura dos Estados Unidos (NRCS/ USDA) informa que a "qualidade do solo é expressa como a capacidade do solo em desempenhar suas funções no momento atual e a preservação dessas funções para o uso futuro". Sendo assim, segundo estes autores, fica expressa no tempo de uso deste recurso a relação que existe entre a qualidade do solo e a sustentabilidade do seu uso.

Sabe-se que a atividade antrópica inadequada tem ocasionado a degradação de imensas áreas, que se tornam improdutivas (OLIVEIRA e SOUTO, 2011, p. 2). Sendo assim, segundo Adams e Morales-García (2008, p. 476), nas últimas décadas diversos trabalhos vêm sendo desenvolvidos pelos países de economia desenvolvida, tipicamente de clima temperado, para definição dos limites para remediação de solos degradados em áreas urbanas, comercial, industrial e residencial.

Nesse sentido, a contribuição de nossa proposta se relaciona à discussão dos princípios normativos sobre os quais estão sediadas as políticas ambientais nacionais. Partimos, a seguir, para a contextualização da degradação da qualidade do solo pela atividade petrolífera para, então, discutirmos a incorporação do modelo de desenvolvimento sustentável pelas políticas públicas de meio ambiente.

\section{Industrialização e produção de petróleo no Brasil durante o século $X X$}

A industrialização no Brasil teve um longo período de quase estagnação característica dos países subdesenvolvidos. Este termo foi defendido por Alfred Sauvy (1952) e aceito pela Organização das Nações Unidas (ONU) desde então, porém o termo "em desenvolvimento" tem sido mais largamente utilizado na atualidade pelo fato de muitos países membros da ONU considerarem o termo depreciativo. Desta forma, pode-se dizer que os países em desenvolvimento, como o Brasil, tiveram (em 
alguns casos continuam tendo) um processo de industrialização e enriquecimento muito pequeno ao longo do século XX. Em relação à produção de hidrocarbonetos de petróleo, indústria que apresenta alto impacto nas economias mundiais (MONIÉ, 2003), o Brasil, de acordo com dados do Departamento Intersindical de Estatística e Estudos Socioeconômicos (DIEESE, 2008), apresentou a primeira pesquisa (neste caso, chamada de prospecção) de petróleo datada de 1892 na cidade de Bofete-SP, porém a perfuração não revelou quantidade de petróleo considerável. Contudo, o petróleo brasileiro somente foi considerado produzível 40 anos mais tarde, com cerca de 2.000 barris de petróleo, em Lobato, na Bahia (DIEESE, 2008). Comparativamente aos EUA, que apresentaram sua primeira perfuração em 1859 (que continha petróleo de boa qualidade), o Brasil já naquela época esteve atrás tecnologicamente na produção petrolífera (LUCHESI, 1998). O Brasil viveu três fases relacionadas à exploração e produção de petróleo e derivados: a primeira, chamada era pré-PETROBRÁS; a segunda, chamada era de exclusividade da PETROBRÁS, e a terceira (fase atual), a era pós-lei 9.478/97, que determina o fim do monopólio da estatal na exploração e produção de petróleo no país (LUCHESI, 1998). Nestes três momentos, podem-se verificar falhas nas questões relacionadas às questões ambientais, que serão abordadas conjuntamente com a abordagem das três fases. Luchesi comenta em seu texto que a era pré-PETROBRÁS compreende duas etapas menores: a primeira compreendida entre 1858 e 1938 e a segunda entre 1939 e 1953.

De maior interesse para nosso estudo, na terceira etapa se dá a criação da Lei 9.478/97, conhecida como Lei do Petróleo, que estabelece o fim do monopólio da PETROBRÁS na exploração e produção de petróleo brasileiro e cria o sistema de concessão de blocos exploratórios. Segundo Lucchesi (1998), este marco transitório cria uma perspectiva produtiva para o governo brasileiro sem precedentes. Diante da possibilidade de formação de parcerias com a PETROBRÁS, a saída da PETROBRÁS do mercado de regulação e a criação da Agência Nacional do Petróleo (ANP), a produção de petróleo no Brasil cresce acentuadamente.

Entretanto, essa mudança de cenário envolve o aumento potencial de impactos, visto que a atividade petrolífera apresenta natureza poluidora em sua concep- ção mais ampla. Desde a atividade de exploração (busca por jazidas de óleo), o início da produção propriamente dita (retirada do óleo dos reservatórios até a superfície), o final da produção (caracterizada pelo refino ou processamento de gases nas refinarias) e sua distribuição e comercialização junto ao mercado consumidor, várias questões relacionadas à agressão ao meio ambiente são observadas. Andrade e colaboradores (2003) e Cachumani (2008) concluem que estes impactos ambientais causados pela atividade petrolífera são inerentes à atividade, pois se trata da produção de combustíveis fósseis.

Ademais, é preciso reconhecer que as "atividades de extração, transporte e refinamento de petróleo têm contribuído para a contaminação do solo com hidrocarbonetos de petróleo em todo o mundo" (LOPES e PIEDADE, 2010, p. 144).

Diante dessa constatação, cumpre analisar, discutir e prevenir os impactos dessa atividade, especialmente aqueles relacionados à poluição do solo, ainda carentes de regulamentação, conforme mostraremos posteriormente.

Em virtude do escopo do trabalho, focalizaremos sobre a contaminação dos solos, que se dá pela dispersão de poluentes sólidos, líquidos e gasosos que se espalham pelo potencial destes poluentes migrarem pelos poros apresentados por estes solos - derramamento (DINIZ, 2005). Na lista de prioridades nacionais dos EUA, por exemplo, existiam em meados da década de 90 mais de 1.200 áreas contaminadas, com possibilidade de esse número aumentar para 32.000 (BACKER e HERSON, 1994).

Devido aos grandes volumes e tipos de hidrocarbonetos produzidos, usados e dispostos em bases globais, não causa surpresa o fato de que grande parte das contaminações superficiais e subsuperficiais atualmente seja causada por estes produtos.

As grandes quantidades de resíduos de petróleo e derivados inadequadamente depositados que têm sido encontradas fornecem uma clara evidência que compostos orgânicos podem permanecer num sítio por longos períodos de tempo. Desta forma, há uma enorme demanda por tecnologias inovadoras envolvendo a remediação ambiental de solos contaminados por hidrocarbonetos de petróleo. Em relação ao derramamento de petróleo bruto e/ou derivados que contaminam o solo, 
pouco relato concreto se observa na literatura. Alguns pesquisadores, tais como Gomes e colaboradores (2008), relatam sobre a queima e o descarte inadequado de óleos lubrificantes e o que eles provocam ao meio ambiente, danos quase irreparáveis. Esta é somente uma das formas de contaminação relatadas na literatura. Pequenos vazamentos ocorridos durante o transporte repetidas vezes não são tratados com a seriedade que deveriam, porém, os estudos indicam sérios danos ao solo, tais como redução da concentração de oxigênio disponível, na redução população de micro-organismos aeróbios e na limitação da disponibilidade de micronutrientes no solo, que requerem tratamento específico (MOTA, 1997; BARROS et al., 2008).

Esta preocupação possui relevo diante do fato de as resoluções CONAMA relacionadas ao uso do solo não abordarem a problemática do derramamento de petróleo ou de seus derivados. Em contrapartida, várias resoluções abordam a questão da poluição das águas, conforme será detalhado adiante. As duas que versam sobre derramamento de petróleo referem-se a derramamento de petróleo em mares, privilegiando a questão da produção marítima de petróleo (resoluções CONAMA 269/2000 e 393/2007). Até a criação da ANP, em 1997, as resoluções do CONAMA, em relação à problemática de poluição do solo por petróleo e derivados, eram os dispositivos legais e orientadores dos processos da indústria petrolífera. A ANP, por sua vez, também trata do tema de forma genérica, como nas definições de solo contaminado (Resolução ANP $n^{\circ}$ 27/2006) e de substância nociva (Resolução ANP n ${ }^{\circ} 44 / 2009$ ). Importa reconhecer a iniciativa do Regulamento Técnico de Devolução de Áreas de Concessão na Fase de Exploração (Resolução ANP n ${ }^{0}$ 13/2011), em que se exige a recuperação ambiental do solo em conformidade com seus usos (agricultura, atividades urbanas) ou para recuperação de suas funções ambientais.

A Política Nacional de Resíduos Sólidos (PNRS) também silencia quanto à indústria petrolífera, tratando apenas de um de seus elementos ao exigir dos fabricantes, importadores, distribuidores e comerciantes de óleos lubrificantes, seus resíduos e embalagens a implantação de sistema de logística reversa (art. 33, IV, Lei 12.305/2010). Contudo, a PNRS não tratou de diversos aspectos referentes aos resíduos desse setor, primando pelos resíduos urbanos, de forma setorizada, conforme crítica realizada por Teixeira e Machado (2012).

Essa ausência de dispositivos e políticas específicas relacionados às questões de poluição do solo, sobretudo a causada pela indústria petrolífera, compromete a indústria brasileira em dois pontos importantes: no investimento estrangeiro em exploração e produção pelo processo de concessão de blocos exploratórios de petróleo e na comunidade internacional, que observa esta como exemplo de fragilidade em outros pontos da política pública brasileira.

Ademais, outro ponto lacunoso refere-se à poluição do solo causada pelo transporte de derivados até a malha consumidora. Em um país como o Brasil, onde o transporte de cargas se faz prioritariamente por rodovias, a questão do vazamento de derivados de petróleo durante o transporte é inegavelmente um item a ser discutido. Outro ponto importante é o vazamento próximo dos centros produtores, onde os caminhões que transportam os derivados ou os dutos são alimentados com os produtos. Estes vazamentos, conforme informações disponíveis no sítio eletrônico da ANP (www.anp.gov.br), ocorrem por derramamento de óleo diesel, gasolina e óleos lubrificantes, preferencialmente.

Traçados os desafios ambientais inerentes à interação entre a atividade petrolífera e a qualidade do solo, analisaremos como as políticas ambientais nacionais têm enfrentado essa questão.

\section{Políticas públicas ambientais no Brasil}

Segundo Benjamim (1999) e Monosowski (1989), a política brasileira foi e é até os dias atuais uma mistura de temas que resultou em uma série de regulamentações que sofrem influências de fatores econômicos, sociais e políticos. Avaliando-se as políticas públicas relacionadas às questões ambientais no século XX (MACHADO, 2012), podem-se observar alguns momentos bem distintos: o primeiro deles marcado pela presença incipiente das políticas ambientais (onde estas eram tratadas de forma superficial e ineficiente, caracterizado pelo predomínio da tentativa de crescimento econômico em detrimento da preservação do meio ambiente), baseado na regulação dos recursos naturais. Outro momento bem 
distinto foi caracterizado pelo controle da poluição proveniente da industrialização, urbanização e agricultura tecnicista; o terceiro momento foi caracterizado pelo planejamento e regulação de espaços geográficos, num momento posterior marcado pela regulação da natureza como um todo (legislações gerais) e questões ambientais globais, haja vista que a globalização estava tomando conta do mundo no final do século XX.

No início do século XX, são formulados os primeiros diplomas legais relacionados a recursos naturais no Brasil. A definição do domínio dos recursos pelo governo por intermédio de estatais é claramente observada pelo Código de Águas, de Mineração e Florestal, promulgado durante a década de 1930 (ALMEIDA, 2007; MACHADO, 2004). Neste momento histórico persiste a ideia de que os impactos ambientais eram necessários em função do progresso econômico (SOUZA, 2006).

Segundo Almeida (2007), a fase vivida pelo Brasil de início de crescimento econômico se traduz num total desrespeito à preservação ambiental. O Código Florestal (Lei 4.771/1965) marca a mudança da política ambiental protecionista (DRUMMOND e BARROS-PLATIAU, 2006). Na década de 1970, marcada pelo empenho mundial de construir políticas ambientais consistentes, o Brasil institui a Secretaria Especial do Meio Ambiente (SEMA) e o Sistema Nacional do Meio Ambiente (SISNAMA). No Rio de Janeiro, ocorre a criação da FEEMA, mais um órgão regulatório no âmbito estadual. Na década de 80 , novos órgãos reguladores são criados e ocorre a total reorganização dos já existentes: CONAMA por meio da Lei 6.938/81, integração do CONAMA com o SISNAMA, criação das áreas de proteção ambiental. As leis 7.735/89 e 7.804/89 criam o IBAMA, absorvendo a SEMA, e acrescentam o Conselho Superior do Meio Ambiente, respectivamente.

O final de século XX no Brasil foi marcado pela mudança de paradigmas em relação à política econômica. Nos governos Collor e Fernando Henrique (primeiro mandato), ainda existiam ideias do desenvolvimento a qualquer custo, embora no governo Collor algumas discussões ambientalistas estivessem presentes. Este fato foi corroborado pela Rio-92 e pela assinatura da agenda 21, compromisso assumido por todos os países (MILARÉ, 1999), inclusive o Brasil.
Segundo Almeida (2007), ao final da década de 80, com a Constituição Federal de 1988 (CF/88), as questões ambientais passam a ser tratadas como estruturadoras das políticas brasileiras. A partir deste momento, as políticas públicas passaram a ter direcionamentos diferenciados: ao longo do último mandato de Fernando Henrique e dos mandatos sequenciais de Lula, o Brasil adota uma política de desenvolvimento econômico conservacionista, mesmo que não seja tão conservacionista na prática. Fatos relacionados ao aumento da poluição e redução de investimentos em saneamento básico no país nestes dois governos são discutidos por Souza (2006) em seu artigo. Neste momento, a corrente socioambiental também fazia sua presença de forma mais forte: as questões sociais envolvendo as questões ambientais contribuíram para a mudança no cenário ambiental brasileiro (CHAVES, 2010).

Com o passar do tempo, a atividade regulatória muito importante na segunda metade do século XX e reorganizada por meio de decretos governamentais deixou algumas lacunas atualmente: primeiramente, há falta de regulamentação para inibição de processos industriais poluidores, não há aplicação clara do princípio da precaução (preconizado pelas conferências ambientais ocorridas anteriormente - uso do direito ambiental como ferramenta), falta de rigor na liberação de licenças de funcionamento de empresas diversas, na realização de estudos de impactos ambientais (EIA) e na elaboração de relatórios de impactos no meio ambiente (RIMA).

Na década de 90, acontecem novas reformulações, porém com a permanência sem alterações das funções do IBAMA. Ocorre reorganização do Ministério do Meio Ambiente e este passa a se chamar Ministério do Meio Ambiente e Amazônia Legal, respondendo a críticas da sociedade sobre a falta de legislação dos recursos ambientais da Amazônia. Em 1995, pela medida provisória 813, o Ministério do Meio Ambiente e Amazônia Legal passa a ser chamado de Ministério do Meio Ambiente, Recursos Hídricos e Amazônia Legal, incorporando as águas em seu escopo regulatório. Na segunda metade desta mesma década, são promulgados importantes diplomas do ordenamento jurídico ambiental, como a Lei 9.433/1997 (Política Nacional de Recursos Hídricos), a Lei 9.605/1998 (Lei de Crimes Ambientais) e a Lei 9.795/1999 (Política Nacional de Educação Ambiental). 
A questão da regulação das questões ambientais no Brasil passa por uma série de mudanças ao final do século XX e na primeira década do século XXI, porém algumas lacunas ainda podem ser observadas e referem-se diretamente às questões relacionadas à poluição do solo. Estas lacunas se referem a questões que envolvem derramamento de óleo e derivados de petróleo, bem como a poluição do solo causada por fatores diversos.

A partir do contexto jurídico-institucional, podemos passar à análise dos pontos de contato e distanciamento entre as políticas ambientais e as premissas do desenvolvimento sustentável relacionadas à proteção do solo.

\section{Desenvolvimento sustentável e uso racional do solo}

Conceituado como alternativa à lógica hegemônica de produção de mercadorias associada à degradação ambiental e à exploração de forma injusta e desigual do trabalho humano, o desenvolvimento sustentável encerra um ideal de racionalização na apropriação dos recursos naturais, inserindo uma variável temporal e uma exigência ética no desenvolvimento econômico.

Pela interpretação do texto normativo constitucional no seu todo (GRAU, 2003, p. 145), entendemos ter sido adotado como modelo para o desenvolvimento nacional aquele definido para o desenvolvimento sustentável. Por essa interpretação, o desenvolvimento visado pela $\mathrm{CF} / 88$ no Brasil está fundado sobre os seguintes pilares: desenvolvimento nacional (art. $3^{\circ}$, II); redução das desigualdades regionais e sociais (art. $3^{\circ}$, III); ordem econômica tem por fim assegurar a todos existência digna em consonância com a preservação ambiental (art. 170, caput c/c. VI); meio ambiente ecologicamente equilibrado (art. 225, caput); responsabilidade intergeracional (art. 225, caput).

A sustentabilidade no uso dos recursos naturais deve ser encarada, nesta ótica, como modelo de desenvolvimento capaz de assegurar condições dignas à sobrevivência das futuras gerações humanas e de todas as demais formas de vida. Sob essa perspectiva, segundo Derani (2001, p. 242):
Desenvolvimento econômico no Estado Brasileiro subentende um aquecimento da atividade econômica dentro de uma política de uso sustentável dos recursos naturais objetivando um aumento de qualidade de vida que não se reduz a um aumento do poder de consumo.

Logo, ao se institucionalizar o uso do adjetivo "sustentável" para o desenvolvimento nacional brasileiro, não se busca criar óbices ao aproveitamento dos recursos naturais, mas, outrossim, construir um modelo de desenvolvimento, com base nos princípios constitucionais, orientado pela "exploração equilibrada dos recursos naturais, nos limites da satisfação das necessidades e do bem-estar da presente geração, assim como de sua conservação no interesse das gerações futuras". Podemos, por exclusão, ainda seguir o entendimento de que se o “desenvolvimento não elimina a pobreza absoluta, não propicia um nível de vida que satisfaça às necessidades essenciais da população em geral, ele não pode ser qualificado de sustentável" (SILVA, 1994, p. 7-8).

Da leitura proposta, pode-se admitir que o modelo de desenvolvimento em curso não é sustentável - apesar da vasta legislação apresentada anteriormente - se não houver nenhuma que trate especificamente da regulação da qualidade do solo de forma geral ou, especificamente, em relação à poluição por hidrocarbonetos. Isso porque estamos diante de omissão legislativa em relação aos impactos de uma atividade poluidora em franca expansão no país.

Importante, sob essa ótica, reconhecer as características gerais da legislação ambiental sobre o tema. A maior parte da regulação existente no Brasil versa sobre a poluição hídrica, como, por exemplo, a Lei 9.966/2000, que dispõe sobre a prevenção, o controle e a fiscalização da poluição causada por lançamento de óleo e outras substâncias nocivas ou perigosas em águas sob jurisdição nacional. O sistema de busca do sítio eletrônico do Conselho Nacional de Meio Ambiente (CONAMA) aponta uma única Resolução com o critério "solo" (em março de 2012). A título de exemplo, para o critério "água” foram encontradas sete resoluções, sendo duas relacionadas à poluição por atividade petrolífera (em março de 2012).

Constatamos que, enquanto o país caminhou bem em relação ao protecionismo das águas (fato que pode ser verificado pelas várias resoluções CONAMA do 
período - Resoluções CONAMA 269/2000, 357/2005, 393/2007, 396/2008, 398/2008 e 430/2011, entre outras) e em relação à proteção do ar (Resoluções CONAMA 403/2008, 432/2011, 433/2011, entre outras), as questões que envolvem a proteção do solo quase são inexistentes, sendo a mais importante a que trata do uso do solo (Resolução CONAMA 005/1995). Algumas apresentam a proteção do solo como item coadjuvante do personagem principal, que é a poluição das águas, fato que pode ser observado na resolução CONAMA 420/2009.

Contudo, isso não quer dizer que o solo esteja fora do ordenamento jurídico brasileiro. Segundo Avanzi e colaboradores (2009, p. 118), o primeiro Código Florestal Brasileiro objetivava a manutenção da cobertura vegetal protetora das terras, a fim de conservar o regime das águas e evitar a erosão das terras pela ação das intempéries. Até este momento, a preocupação da legislação seria de evitar a degradação dos recursos naturais.

A Lei 6.225/1975, segundo este objetivo, facultou ao Ministério da Agricultura a discriminação de regiões onde a exploração econômica estaria vinculada à "prévia execução de planos de proteção ao solo e de combate à erosão" (art. 1 ${ }^{\circ}$, caput, Lei 6.225/1975). Atualmente, o que vigora é o Programa Nacional de Bacias Hidrográficas e Conservação de Solos na Agricultura, programa este que visa diretamente à preservação e ao uso sustentável dos recursos hídricos e do solo (AVANZI et al., 2009, p. 119). No mesmo ano, entra em vigor o Decreto 76.470/1975, que "cria o Programa Nacional de Conservação dos Solos - P.N.C.S. - e dá outras providências". No seu primeiro artigo, a lei demonstra o seu objetivo, que é "promover, em todo o território nacional, a adoção das práticas de conservação do solo, assim entendidos a manutenção e o melhoramento da sua capacidade produtiva".

O parcelamento do solo urbano, regulado pela Lei 6.766/1979, por tratar do loteamento e desmembramento do solo urbano e, portanto, mais especificamente relacionado aos aspectos quantitativos do recurso, foge do escopo qualitativo dado ao tratamento da contaminação dos solos. Contudo, a alocação de atividades potencialmente causadoras de significativos impactos sobre a qualidade do solo, como postos de gasolina, deveria merecer tratamento especial. A título de ilustração, apenas o Estado de São Paulo possui legislação específica para os hidrocarbonetos aromáticos policíclicos (HAPs), segundo Jacques e colaboradores (2007). Continuando com os autores, concordamos que:

Independentemente da atividade industrial, os centros urbanos são os locais com maior potencial de contaminação dos HAPs, devido aos postos de combustíveis, que podem contaminar o ar, o solo, o subsolo e as águas subterrâneas com hidrocarbonetos resultantes dos vazamentos nos tanques subterrâneos de armazenamento de combustíveis (JACQUES et al., 2007, p. 1.193).

Apesar dos impactos reais e potenciais a que se encontra submetido, o solo permanece como recurso secundário ou subsidiário, merecendo tratamento jurídico apenas como recurso natural que se presta a alguma atividade econômica principal, como a agricultura, sem o estabelecimento específico de normas, de padrões de emissão e locacionais das diferentes atividades econômicas.

Apenas com o advento da Lei 6.938/1981 (Política Nacional de Meio Ambiente) o solo passa a receber tratamento diferenciado, assim como toda a temática ambiental. O marco do ordenamento jurídico ambiental denota, pela primeira vez em âmbito federal, a perspectiva holística do ambiente, que seria recepcionada pela $\mathrm{CF} / 88$.

Assim sendo, nesta lei federal está estabelecido que:

Art. $2^{\circ}$ - A Política Nacional do Meio Ambiente tem por objetivo a preservação, melhoria e recuperação da qualidade ambiental propícia à vida, visando assegurar, no País, condições ao desenvolvimento socioeconômi$\mathrm{co}$, aos interesses da segurança nacional e à proteção da dignidade da vida humana, atendidos os seguintes princípios:

[...] II - racionalização do uso do solo, do subsolo, da água e do ar;

[...]

Art. $3^{\circ}$ - Para os fins previstos nesta Lei, entende-se por: [...] V - recursos ambientais: a atmosfera, as águas interiores, superficiais e subterrâneas, os estuários, o mar territorial, o solo, o subsolo, os elementos da biosfera, a fauna e a flora (Lei 6.938/1981). 
Ao reconhecer a importância do solo como recurso ambiental individualizado e definir como princípio da Política Nacional de Meio Ambiente (PNMA) a racionalização do seu uso, devemos interpretar que a Lei 6.938/1981 determina que o recurso ambiental "solo" deve ser preservado e restaurado "com vistas à sua utilização racional e disponibilidade permanente, concorrendo para a manutenção do equilíbrio ecológico propício à vida" (art. 4, VI, Lei 6.938/1981). Concepção que nos parece ancorada, quando da leitura da legislação ambiental em vigor, nas Leis 7.661/1988, 8.171/1991, 9.433/1997 e 9.605/1998, impregnadas de dispositivos relacionados à gestão e fiscalização do seu uso racional.

Daí compreendermos que o legislador, ainda que não explicitamente ou de forma rudimentar, concebia a perspectiva de longo prazo e, portanto, de sustentabilidade no uso dos recursos ambientais, de forma geral, e do solo, especificamente. Preocupação que, devido ao aumento das atividades humanas e à pressão antrópica sobre os recursos naturais, tais como o solo e a água, vem se destacando nas últimas décadas.

A utilização descuidada e sem planejamento dos recursos naturais ocasionou a degradação e as alterações nos ecossistemas naturais, principalmente devido ao manejo incorreto dos solos, resultando na desvinculação entre crescimento econômico e desenvolvimento sustentável (AVANZI et al., 2009, p. 116; SILVA et al., 2011, p. 2). Estas ações antrópicas, ao longo do tempo, têm alterado a fertilidade dos solos e reduzido a capacidade dos indicadores biológicos em indicar o nível de degradação ambiental (OLIVEIRA e SOUTO, 2011, p. 2).

Ainda assim, a tutela jurídica da qualidade do solo, como ocorre na Lei de Crimes Ambientais (Lei 9.605/98), está inserida em uma interpretação geral do crime de poluição, tipificado no art. 54: "Causar poluição de qualquer natureza em níveis tais que resultem ou possam resultar em danos à saúde humana, ou que provoquem a mortandade de animais ou a destruição significativa da flora" (no mesmo sentido, as infrações e sanções administrativas previstas no Decreto 6.514/2008, especialmente em seu art. 61).

Especificamente, há a qualificação do crime tipificado no art. 54, $\S 2^{\circ}$, V, de ocorrência de poluição "por lançamento de resíduos sólidos, líquidos ou gasosos, ou detritos, óleos ou substâncias oleosas, em desacordo com as exigências estabelecidas em leis ou regulamentos" (v. art. 62, V, Decreto 6.514/2008).

Segundo Silva e colaboradores (2011, p. 2), quando os sistemas naturais são modificados pela ação humana, estas áreas tornam-se degradadas e podem ter a sua capacidade melhorada, conservada ou diminuída. Quando a alteração está associada a processos que resultam na perda da capacidade natural do sistema, diz-se que estas áreas estão degradadas. Sendo assim, a qualidade do solo e a sua sustentabilidade podem ser afetadas por fatores tais como o sistema político que norteia a tomada de decisão do Poder Público, as forças sociais, a pressão demográfica, a disputa de terra, as aspirações e as necessidades de cada tipo de cultura.

Nesse sentido, o licenciamento ambiental, configurado como principal instrumento da PNMA (art. $9^{\circ}$, IV, Lei 6.938/81), e a elaboração do Estudo de Impacto Ambiental (EIA), constitucionalmente prevista no art. $225, \S$ $3^{\circ}, \mathrm{CF} / 88$ ), constituem-se fundamentais para a qualidade do solo, especialmente em razão da poluição por resíduos da cadeia petrolífera. O licenciamento ambiental do setor está obrigado a elaborar o EIA e respectivo Relatório de Impacto Ambiental (RIMA), conforme disposição da Resolução CONAMA 001/86 (v. art. 2º, III, V e VIII). A previsão dos impactos sobre o solo dessas atividades é item obrigatório do EIA/RIMA, de acordo com os arts. $5^{\circ}$, II, e $6^{\circ}$, II, da mesma Resolução. Cabe, portanto, ao órgão ambiental o acompanhamento e a fiscalização das atividades em conformidade com as condicionantes do licenciamento ambiental e, assim sendo, aumentar a objetividade da proteção desse recurso, suprindo, de certa forma, a lacuna legal discutida.

Para tanto, devemos entender a concepção constitucional de desenvolvimento sustentável - vinculadora para as políticas públicas, especificamente, as políticas ambientais - da maneira mais ampla possível, conforme argumentação de Machado e Vilani (2010; 2011). Partimos da competência da União, dos Estados e do Distrito Federal de legislar concorrentemente sobre defesa do solo (art. 24, VI, CF/88). A partir da construção teórica dos autores e pelo exposto até aqui, podemos aplicar, no que toca ao tema deste trabalho, que o desenvolvimento sustentável nacional pressupõe o cumprimento da função social da propriedade rural e o planejamento e o adequado aproveitamento do solo urbano, de acordo 
com os ditames das funções sociais da cidade, para as presentes e futuras gerações (art. 182, caput, $\S 4^{\circ}$ e art. 186, caput, c/c. art. 225, caput, in fine, CF/88).

Para tanto, para se pensar em desenvolvimento sustentável é preciso que haja regulamentação específica em relação à qualidade do solo, tanto para as políticas de desenvolvimento urbano como para as políticas agrárias e em suas interfaces com as demais políticas setoriais. A distância que nos encontramos para o estabelecimento de uma política nacional integradora é a mesma para a construção das bases de dignidade para a existência das presentes e futuras gerações.

Ainda que no ordenamento jurídico estejam previstos instrumentos para a proteção do solo, a ausência de normas específicas limita a atuação dos próprios órgãos ambientais encarregados do licenciamento ambiental, visto estarem submetidos ao princípio da legalidade.

No atual momento de expansão da atividade petrolífera no país, com novas refinarias e as expectativas em torno da produção do Pré-sal, a destinação dos resíduos produzidos diretamente pela indústria petrolífera, além daqueles contaminados por seus derivados, como óleos, graxas e combustíveis, deve repercutir diretamente na regulamentação da qualidade do solo. Isso porque a falta de planejamento ou a destinação inadequada em aterros sanitários e industriais, além da disposição em lixões e vazadouros, comprometerá o solo, com seus desdobramentos sobre os recursos hídricos.

Para exemplificar a complexidade do tema e a relevância da discussão, destacamos, a partir de Bona e Santos (apud MARANHO et al., 2009, p. 268), que o petróleo reduz a capacidade de retenção de água pelo solo, interferindo no crescimento das plantas (v. tb. GOGOSZ et al., 2010; LOPES e PIEDADE, 2010).

A edição de normas específicas e a implementação de políticas públicas precisam, portanto, reconhecer e internalizar a natureza holística da questão ambiental sob uma perspectiva de longo prazo, em respeito ao direito das futuras gerações à qualidade de vida.

A preocupação de longo prazo precisa ser ressaltada e, por isso, encontra-se relevada no conceito de desenvolvimento sustentável sob o manto da responsabilidade intergeracional, diante da magnitude dos impactos relacionados ao solo, como a desertificação. Oliveira e Souto (2011, p. 3) destacam da Convenção
Mundial de Combate à Desertificação (Projeto BRA 93/036 - operacional até 2000, quando começou a ser reestruturado) seu primeiro artigo, com a seguinte definição de degradação de terras:

[...] redução ou a perda da produtividade biológica ou econômica das terras agrícolas de sequeiro das terras de cultivo dos pastos e dos bosques em zonas áridas, semiáridas e subúmidas secas, pelos sistemas de utilização de terra ou por um processo ou uma combinação de processos, incluídos os resultantes de atividades humanas e padrões de povoamento, tais como: [...] (ii) a deterioração das propriedades físicas, químicas e biológicas ou das propriedades econômicas do solo e (iii) a perda duradoura da vegetação natural.

Hillei (1998, apud DINIZ FILHO et al., 2007, p. 28) destaca que "a civilização atual cada vez mais dependerá do solo, principalmente porque vem aumentando esta dependência, enquanto os recursos naturais disponíveis de solo vêm diminuindo e sendo deteriorados".

Kathounian (2001, apud VEZZANI e MIELNICZUK, 2009, p. 750) afirma que "a fertilidade é a capacidade de gerar vida, e é da matéria vegetal que se nutrem os complexos de vida". Sendo assim, o mesmo autor complementaria que "não está no solo, nem nas plantas, nem nos animais, mas no seu conjunto dinâmico, integrado e harmônico, que se reflete em boas propriedades do solo e boa produção vegetal e animal”.

Por meio da preservação, monitoramento e respostas ao uso do solo pode-se perceber as alterações que o ser humano vem causando ao solo de forma cada vez mais intensa e acelerada. Sendo assim, seria interessante relacionar as alterações que vêm ocorrendo ao longo do tempo (que podem resultar na extinção de diversas civilizações) com a sustentabilidade dos sistemas (DINIZ FILHO et al., 2007, p. 28; SILVA et al., 2011, p. 10).

Vezzani e Mielniczuk (2009, p. 750) destacam que o solo, agindo isoladamente, não consegue atingir a sua plena qualidade, necessitando da vegetação que ali se desenvolve para tal. Entretanto, segundo os mesmos autores, não se pode esquecer dos demais sistemas envolvidos no processo para recuperação do solo, tais como seus microrganismos presentes, integrados e adaptados ao seu local no ambiente, tese corroborada por estudos 
desenvolvidos, por exemplo, por Maranho et al. (2009), Lopes e Piedade (2010), Jacques et al. (2007) e Mariano et al. (2007).

Constatamos que a regulamentação do solo em nosso ordenamento ainda carece de maior sistematicidade, apesar dos avanços alcançados na década de 1990, e que esta tarefa demanda urgência diante dos impactos provenientes da gestão inadequada do solo, em área urbana ou rural. Defendemos a necessidade de aplicação do modelo de desenvolvimento sustentável encerrado na Constituição Federal pelas políticas públicas ambientais, em especial aquelas que tratem, direta ou indiretamente, do solo.

Podemos, diante do cenário apresentado, tecer algumas considerações e proposições no sentido de fortalecer esse processo de construção de uma sociedade economicamente desenvolvida e socialmente igualitária em um ambiente ecologicamente equilibrado (MACHADO, 2012).

\section{Considerações finais}

O solo é um recurso natural extremamente complexo e que permite que os demais recursos fiquem disponíveis na sua melhor forma. Este recurso, estando ecologicamente equilibrado e com a sua qualidade assegurada, possibilita a produtividade biológica, mantém a qualidade dos outros recursos ambientais e, por fim, permite a sobrevivência do homem em um ecossistema equilibrado por um longo tempo.

O arcabouço ambiental em relação ao solo foi sendo construído aos poucos e vem sendo constantemente ampliado. O passo inicial desta construção foi dado em 1975, demonstrando uma primeira preocupação com o solo propriamente dito, porém mais voltada para a erosão que prejudicaria a vida humana.

A década de 80 foi marcada por dispositivos que fizeram com que este recurso passasse a ser realmente reconhecido. No início da década de 80 , o solo foi identificado como recurso ambiental, sendo exigido o seu uso racional. Na década seguinte, teve início a preocupação com o solo pelo uso de agrotóxicos e, posteriormente, seu tratamento vinculado à gestão das águas. A caminhada legislativa, entretanto, apesar destes avanços e do estabelecimento de penalidades pelos danos causados ao solo, estagnou no processo de erosão e ampliou o rol de danos ambientais, como aqueles inerentes à indústria petrolífera, que podem comprometer a qualidade solo.

As lacunas deixadas pela política ambiental adotada nos últimos anos tornam preocupante a questão da indústria do petróleo no país. Conforme descrito por Silva e colaboradores (2011), a cadeia do petróleo é vasta e extremamente poluente desde os primeiros processos de prospecção até sua distribuição e utilização dos derivados pelo consumidor final.

Ao se fazer uma análise das principais resoluções do CONAMA, se observa claramente a preocupação do órgão em regular questões relacionadas à poluição das águas em primeira instância. Até nas resoluções de abrangência maior, como a Resolução 420/2009, percebe-se claramente o objetivo primário da resolução, que é proteger o solo que entra em contato com ambientes aquáticos. Isto é observado no artigo segundo, parágrafo único. A Resolução 362/2005 é outro dispositivo que trata do descarte de óleo lubrificante usado ou contaminado, porém com enfoque na proteção aos ambientes aquáticos. Esta resolução é uma, entre outras, que não privilegiam o solo como objeto principal do próprio dispositivo jurídico regulamentador. Em todo texto, percebe-se a preocupação com a problematização da poluição do solo alcançar leitos aquáticos. Esta preocupação é válida, porém não deve pautar uma resolução que se propõe regulamentar questões direcionadas à poluição do solo.

Obviamente, a poluição da água, em conjunto com a poluição do solo, é importante e merece o devido tratamento, porém os impactos ambientais de tais poluições são diferentes, alcançam ambientes diferentes e por isto devem ser tratados de forma diferenciada.

Em termos gerais, o desafio central, observado a partir da legislação analisada, é o tratamento esparso do solo em meio às diferentes normas ambientais em vigor, que disciplinam desde aspectos ambientais da agricultura até a gestão das águas. Entretanto, apesar de reconhecida a importância do solo como substrato de atividades econômicas e de conservação de outros recursos naturais, não há, ainda, uma regulamentação que estabeleça as diretrizes, princípios e objetivos do planejamento e gestão de seu uso racional. 
Especificamente, duas questões merecem atenção ao se pensar a interface entre o desenvolvimento da atividade petrolífera no país e a conservação da qualidade do solo para as presentes e futuras gerações:

a. Ausência de regulamentação clara sobre a poluição do solo causada por petróleo e derivados;

b. Tratamento da poluição do solo como uma poluição secundária.

Passadas três décadas do conceito legal de meio ambiente como o "conjunto de condições, leis, influências e interações de ordem física, química e biológica, que permite, abriga e rege a vida em todas as suas formas" (art. 3º, I, Lei 6.938/1981), não é concebível a permanência de lacunas em relação à visão holística de meio ambiente. Sobretudo, diante de um recurso cuja racionalização de seu uso é considerada essencial para a manutenção do equilíbrio ecológico propício à vida (art. $2^{\circ}$, II c/c. $4^{\circ}$, VI, Lei 6.938/1981).

As resoluções CONAMA precisam urgentemente de reformulações para que tenham abrangência maior do que as regulamentações existentes hoje. Há necessidade clara de tratamento mais detalhado em relação à poluição de solo causada por vazamentos de petróleo e derivados, além de melhor regulamentação sobre os transportes de derivados, quer sejam por navios, caminhões ou dutos de transporte.

$\mathrm{O}$ arcabouço judiciário brasileiro voltado para a matéria ambiental vem sendo constantemente revisto e adaptado. Para atingir o seu pleno objetivo, assim como permitir que ocorra um "desenvolvimento sustentável"

\section{Referências}

ADAMS, R. H.; MORALES-GARCÍA, F. Concentración residual de hidrocarburos en suelo del trópico. I: Consideraciones para La salud pública y protección al ganado. Interciencia, v. 33, n. 7, p. 476-482, 2008.

; ZAVALA-CRUZ, J.; MORALES-GARCÍA, F. Concentración residual de hidrocarburos en suelo del trópico. II: Afectación a la fertilidad y su recuperación. Interciencia, v. 33, n. 7, p. 483-489, 2008.

ALMEIDA, J. G. A. Políticas públicas e gestão ambiental. 2007. Disponível em: <http://www.ambiente.sp.gov.br/EA/ adm/admarqs/JulianAlmeida.pdf $>$. Acesso em: 22/12/2011. de maneira mais eficiente, acreditamos que é importante diferenciar os ambientes (urbanos e rural) e dar uma atenção aos diferentes tipos de solo que temos no país, permitindo com que este não seja cada vez mais degradado por um insistente processo de planejamento imediatista.

Não se trata aqui de proposições oriundas de mera especulação teórica, mas do cumprimento das disposições contidas na PNMA, em especial aquelas relacionadas ao estabelecimento de critérios e padrões de qualidade ambiental e de normas relativas ao uso e manejo do solo, consoante entendimento do objetivo encerrado no art. $4^{\circ}$, III.

As lacunas relacionadas à proteção do solo, em última análise, demonstram o descompasso entre, de um lado, o alcance das leis ambientais e das resoluções do CONAMA, e, de outro, o modelo de desenvolvimento sustentável definido pela Constituição Federal e as disposições da PNMA.

Dessa forma, pode-se admitir que a ausência de padrões e normas específicos para a qualidade do solo, em relação à poluição pela indústria petrolífera particularmente, denota a insustentabilidade da prática político-institucional em andamento no país.

Caminhamos, assim, em meio a um cipoal de normas e políticas ambientais destituídas de preocupação com um substrato vital para o meio ambiente ecologicamente equilibrado e, portanto, sem eficácia no sentido de assegurar existência digna para as presentes e futuras gerações.

ANDRADE, M. T.; MARZULLO, A. C.; SANTOS, F. C.; YOUNG, C. E. F. Emissão de poluentes na indústria do petróleo. Instituto de Economia da UFRJ. Rio de Janeiro, 2003.

AVANZI, J. C.; BORGES, L. A. C.; CARVALHO, R. Proteção legal do solo e dos recursos hídricos no Brasil. Revista em Agronegócios e Meio Ambiente, v. 2, n. 2, p. 115-128, 2009.

BACKER, K. H.; HERSON, D. S. Bioremediation. New York: McGraw-Hill, 1994.

BARROS, D.; OLIVEIRA, V.; SANTANA, M. F. E.; CARVALHO, D. D. Caracterização ambiental dos postos de revenda 
de combustíveis no Rio de Janeiro. In: CONGRESSO BRASILEIRO DE ÁGUAS SUBTERRÂNEAS, 15., 2008. Rio Grande do Norte. Anais.

BENJAMIN, A. H. (Org.). Manual Prático da Promotoria de Justiça do Meio Ambiente. São Paulo: IMESP, 1999.

CACHUMANI, R. M. L. Aspectos sobre avaliação ambiental das atividades de exploração e produção de petróleo marítimo da Bacia de Campos. In: CONGRESSO NACIONAL DE EXCELÊNCIA EM GESTÃO, 4., 2008. Niterói. Anais.

CHANDRA, R.; BHARAGAVA, R. N.; YADAV, S.; MOHAN, D. Accumulation and distribution of toxic metals in wheat (Triticum aestivum L.) and Indian mustard (Brassica campestris L.) irrigated with distillery and tannery effluents. Journal of Hazardous Materials, v. 162, p. 1514-1521, 2009.

CHAVES, M. P. S. R. Conflitos socioambientais e identidades políticas na Amazônia. 2010. Disponível em: <http://www. achegas.net>. Acesso em: 31/12/2011.

DERANI, C. Direito ambiental econômico. São Paulo: Max Limonad, 2001.

DIEESE. As recentes descobertas de petróleo e gás natural e o marco regulatório da indústria de petróleo no Brasil. DIEESE, 2008, n. 71.

DINIZ, A. Poluição de solos, riscos e consequências. Revista da Faculdade de Ciência e Tecnologia da UFP, v. 5, p. 97106, 2005.

DINIZ FILHO, E. T.; MESQUITA, L. X.; OLIVEIRA, A. M.; NUNES, C. G. F.; LIRA, J. F. B. A prática da compostagem no manejo sustentável de solos. Revista Verde de Agroecologia e Desenvolvimento Sustentável, v. 2, n. 2, p. 27-36, 2007.

DRUMMOND, J.; BARROS-PLATIAU, A. F. Brazilian environmental laws and policies, 1934-2002: a critical overview. Law \& Policy, v. 28, n. 1, p. 83-108, 2006.

GOGOSZ, A. M.; BONA, C.; SANTOS, G.; BOTOSSO, P. Germination and initial growth of Campomanesia xanthocarpa O. Berg. (Myrtaceae), in petroleum-contaminated soil and bioremediated soil. Braz. J. Biol., v. 70, n. 4, p. 977-986, 2010.

GOMES, P. L.; OLIVEIRA, V. B. P.; NASCIMENTO, E. A. Aspectos e impactos no descarte de óleos lubrificantes: o caso das oficinas. In: CONGRESSO NACIONAL DE EXCELÊNCIA EM GESTÃO, 4., 2008. Niterói. Anais.

GRAU, E. R. A ordem econômica na Constituição de 1988. São Paulo: Malheiros, 2003.

JACQUES, R. J. S.; ZAIDA, F. M. B.; ANTONIOLLI, I.; CAMARGO, F. A. O. Biorremediação de solos contaminados com hidrocarbonetos aromáticos policíclicos. Ciência Rural, v. 37, n. 4, p. 1192-1201, 2007.

LOPES, A.; PIEDADE, M. T. F. The period of contamination with petroleum influences the regrowth of Echinochloa polystachya (HBK) Hitchcock in varzea soil in Central Amazon. Biota Neotrop., v. 10, n. 4, p. 143-148, 2010.

LUCHESI, C. Petróleo. Estudos Avançados, São Paulo, v. 12, n. 33, 1998. Disponível em: <http://www.scielo.br/pdf/ea/ v12n33/v12n33a03.pdf $>$. Acesso em 28/12/2011.

MACHADO, C. J. S. (Org.). Gestão de águas doces. Rio de Janeiro: Interciência, 2004.

(Org.). Ciências, políticas públicas e sociedade sustentável. Rio de Janeiro: E-Papers, 2012.

; VILANI, R. M. Aspectos jurídicos ambientais na exploração do Pré-sal: uma leitura do novo marco regulatório sob a perspectiva constitucional. Revista Forense, Rio de Janeiro, v. 412, p. 413-427, 2010.

; __ O novo marco regulatório brasileiro para a exploração das reservas petrolíferas brasileiras. Revista da $\mathrm{Fa}$ culdade de Direito da Universidade Federal de Minas Gerais, Belo Horizonte, v. 1, p. 101-137, 2011.

MARANHO, L.; DZIEDZIC, M.; MUÑIZ, G.; KUNIYOSHI, Y.; GALVÃO, F. Effects of the pollution by petroleum on the tracheids along thestem of Podocarpus lambertii Klotzsch Ex Endl., Podocarpaceae. Braz. J. Biol., v. 69, n. 2, p. 263-269, 2009.

MARIANO, A. P.; KATAOKA, A. P. A.; ANGELIS, D. F.; BONOTTO, D. M. Laboratory study on the bioremediation of diesel oil contaminated soil from a petrol station. Brazilian Journal of Microbiology, n. 38, p. 346-353, 2007.

MELO, R. F.; DIAS, L. E.; MELLO, J. W. V.; OLIVEIRA, J. A. Potencial de quatro espécies herbáceas forrageiras para fitorremediação de solo contaminado por arsênio. Revista Brasileira de Ciência do Solo, v. 33, p. 455-465, 2009.

MILARÉ, E. Direito do ambiente: um direito adulto. Revista de Direito Ambiental, São Paulo, ano 4, n. 15, p. 34-55, jul./ set. 1999.

MONIÉ, F. Petróleo, industrialização e organização do espaço regional. In: PIQUET, R. Petróleo, royalties e região. Rio de Janeiro: Garamond, 2003. p. 257-286.

MONOSOWSKI, E. Políticas ambientais e desenvolvimento no Brasil. Cadernos FUNDAP, São Paulo, n. 9, v. 16, p. 1524, 1989. 
MOTA, S. Introdução à Engenharia Ambiental. Rio de Janeiro: Associação Brasileira de Engenharia Sanitária e Ambiental. Sindicato Nacional dos Editores de Livros, Rio de Janeiro, 1997.

OLIVEIRA, E. M.; SOUTO, J. S. Mesofauna edáfica como indicadora de áreas degradadas. Revista Verde de Agroecologia e Desenvolvimento Sustentável, v. 6, n. 1, p. 1-9, 2011.

SAUVY, A. Trois mondes, une planète. L'Observateur. Paris: Ed. Societé Démographie, 1952.

SILVA, J. A. Direito Ambiental Constitucional. São Paulo: Malheiros, 1994.

SILVA, R. C. S.; ALMEIDA, J. C. R.; BATISTA, G. T.; FORTES NETO, P. Os indicadores físicos, químicos e biológicos da qualidade do solo e da sustentabilidade dos ambientes naturais. Repositório Eletrônico Ciências Agrárias, Coleção Ciências Ambientais, p. 1-13, 2011.

SOUZA, A. C. A. A evolução da política ambiental no Brasil do século XX. 2006. Disponível em: <http://www.achegas. net/numero/vinteeseis/ana_sousa_26.htm>. Acesso em: 28/12/2011

TEIXEIRA, B. M.; MACHADO, C. J. S. Marco regulatório brasileiro do processo de descomissionamento ambiental da indústria do petróleo. Revista de Informação Legislativa, Brasília, v. 49, n. 196, p. 183-203, out./dez. 2012.

VEZZANI, F. M.; MIELNICZUK, J. Uma visão sobre qualidade do solo. Revista Brasileira de Ciência do Solo, v. 33, p. 743-755, 2009.

Recebido em 10 de dezembro de 2012. Aceito em 01 de novembro de 2013. Publicado em dezembro de 2013. 